\title{
Factors Influencing The Performance of Village Health Teams (VHTS) In Health Promotion. A Cross-Sectional Study Of Namuyoga Town Council Tororo District.
}

\author{
Franco Alumaa, ${ }^{a}$, Arnold Manyara Bbee ${ }^{a}$ \\ a School Management And Applied Sciences, St. Francis School Of Health Sciences Mukono, \\ Nakifuma County, Nagojje Sub-county - Namataba - Mukono District, Uganda
}

Abstract

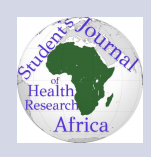

Background:

The study focused on examining the various factors, directly and indirectly, that influence the performance of VHT activities. The study was based on the scientific fact that incentives, availability, and support supervisions have a significant impact on the quality of health services offered by VHTS The study was conducted in Nabuyoga Town Council in Eastern Uganda.

Methodology:

The researcher adopted cross-sectional descriptive methods; the researcher employed a questionnaire with both ended and closed-ended questionnaires to gather data. Also, the researcher acquired an interview guide to gathering qualitative data.

\section{Results}

Substantively the study has revealed positive results, that incentives influence the performance of VHTS in terms of motivation and retention. Secondary the study has shown that lack of sufficient supplies has negatively affected the performance of service delivery in terms of availability and accessibility. Thirdly, the study has revealed there is a dire need to adopt an effective supervisory mechanism for technical development and the sustainability of VHT activities in the area.

Conclusion and recommendations: ${ }^{a}$

Quality services delivery by VHTS in health promotion, there is a great need to improve on the availability of incentives, supplies, and support supervision; it is only by sincere involvement of community members that health quality in the area can be realized.

\footnotetext{
${ }^{a}$ Date Submitted:1 $17^{\text {th }} / 10 / 2021$

Date Accepted: $\quad 1^{\text {st }} / 12 / 2021$ Email:

alumafranco4@gmail.com
}

\section{Background of the study}

The purpose of health promotion is to strengthen the skills and capabilities of individuals to take action and the policy of groups or communities to act collectively to exercise control over the determi- nants of health and achieve positive change (WHO, 1978).

According to the Ottawa Charter (1986), health promotion is determined by a combination of strategies which include developing personal skills, strengthening community action, and creating 
supportive environments for health promotion; various countries worldwide have had problems with promoting health to all individuals. In developing economies especially Sub- Saharan Africa the situation is worse. In Uganda, despite efforts by the Ministry of Health to address the country's health challenges, health care performance is still poor.

The health status of Uganda has slightly improved but there is a lot to be desired; the mortality rate of the country is 350 per 100' 000 live births, the infant mortality rate is 76per 1,000 live births and communicable diseases contribute $80 \%$ of disability adjusted life years lost (WHO Statics 2010; HSSIP 2010/ 11-2014/15). The concept of primary health care originated before 1978 but was formalized with the Ata Declaration of 1978 and its emphasis was on education on health problems, promotion of food supply and nutrition, provision of safe water and sanitation, maternal and child health care, control of endemic diseases, treatment of common diseases and minor injuries, and provision of essential drugs.

It is against this background that the village teams (VHTS) Phenomenon came into play to decentralize health care services to the grassroots levels. The health system of Uganda has been structured with the community / VHT groups at the grass-root level as health center I, under the supervision of health center II, followed by health center III, health center IV'S (referral facility - public or private not for profit), district health headquarters regional referral hospitals, national referral hospitals and ministry of health at the top. Runumi, (2007) HSSIP (2010/11-2014/15).

The VHT system was established by the Ministry of Health through the National Health Policy and Health sector strategic plan in 2003 and managed at the village level. It embraces all former community health volunteer categories (Angela, no date). It comprises a team of $9-10$ members in a village (HSSP, 2000) selected on a popular vote after sensitization and consensus-building of all village members from all households and selected on purely voluntary terms to oversee the health status and activities of the community. The major objective of the VHT is to improve health at the household level and also ease the collection and management of health information.

VHT members are selected based on the Ministry of Health criterion which emphasizes residence in the community, exemplary conduct, lit- eracy skills, interest in health issues, status in the community and prior involvement with community health activities and willingness to work voluntarily.

The VHT members are taken through training 36 topics which communication community mobilization and empowerment, child growth and development (Faith, no date). Communicable diseases, sexual and reproductive health, environmental health, non-communicable diseases, and monitoring and evaluation. The objectives of VHT are to strengthen service delivery at the household and village level; establish a village information system, and empower household members to value health band sustain health actions. (Village health team collection - VHT'S booklet, unpublished) thus bringing service nearer to the people. VHT'S roles include identifying community needs, mobilizing health programs, maintaining records; referral of the sick to health center II, distributing health information and services; acting as a link between the community and health providers HSSIP( 2010/11-2014/15). Village health team collection - VHT booklet, UN published.

The research study will focus on village Health Teams (VHT) in six (6) parishes of Nabuyoga

town council; these include; panga, Miganja, Sengo, Mawele A, and Ojilai A. A total of 100 respondents will be involved in the study and these include VHTS' health - charges and supervisors of VHT'S local council chairpersons, Nabyonga town council health officers, and residents.

The study intends to investigate how annual support supervision and training of VHTS' incentives, and availability of supplies (independent variables) influence their performance (dependent variable).

\section{METHODOLOGY.}

\section{Research design}

To capture comprehensive results, the researcher adopted a cross-sectional descriptive method to measure the current VHT performance in health promotions. A quantitative approach to help to acquire in-depth information for proper analysis and making appropriate conclusions and interviews were also used to capture in-depth data which would not be possible to be got of a questionnaire. For triangulation of data, both qualitative and quantitative methods were be used; openended and closed-ended questions and the ques- 
tionnaires for the community were used to triangulate the information received from VHTS.

\section{Study population.}

The researcher collaborated with Nabuyoga town council health officers to identify the $30 \mathrm{VHTS}$, both working under the government structure and those under private not-for-profit organizations in the area. The study population also included members of the Nabuyoga town council public health team, local council chairpersons, -charges for health facilities, and the VHT health supervisors within the Nabuyoga town council.

\section{Sample size determination}

The sample size is a subgroup. Sekenan, (2003). This study allowed conclusions from the sample to generalize for the whole population.

\section{Study unit}

\section{Data collection techniques and instruments}

\section{Focus group discussion.}

Two focus groups were held at Mawale $A$, and Ojilai A respectively, data was collected from VHTs; this was later used to probe for further responses and clarify more on the issues that were given by respondents.

\section{Questionnaires}

Under the qualitative approach, questions were categorized, scale, and coded to minimize bias. This was appropriate because it helped in collecting quantifiable information from a wide range of respondents. In addition, they are easy to administer and enable the collection of information from a big example. Both open-ended and closed-ended questions were used for data triangulation. Questionnaires were used to gather data from the local community about the performance of VHTs in health promotion.

\section{Interviewers}

In-depth interviews were conducted with opinion leaders such as the local council chairpersons and their secretaries for health, public health officers, health facility in-charges, and VHT supervisors of Nabuyoga town council. This was suitable because it caters to the literates and illiterates who enabled the researcher to probe and adopt questions as necessary. (Questionnaires and interviews schedules can be found in Appendix 1).

\section{Data analysis techniques and presentation}

Data were analyzed using the SPSS package. Data was presented in tables, pie charts, and graphs for the presentation of each independent variable indicated and analyzed in relation to the literature reviewed.

\section{Quality control techniques}

In order to ensure validity and reliability of the instruments for data collection such as the questionnaire, the researcher conducted consultations with the supervisors and hold pre-tests to access the soundness of the tools. Biased data was avoided by using purposive random sampling. Editing and coding were also thoroughly done during and after each fieldwork to ensure competency, uniformity, and comprehensibility.

\section{Ethical consideration \\ Respect for respondents}

Written permission was sought from the institute authority to proceed with data collection; this was taken to the local council chairpersons, to obtain permission to carry out research in the town. The letter from the local council chairpersons was presented to the respondents to request their participation in the research.

\section{Autonomy of participants}

Respondents' time and privacy was be respected through making appointments in order to avoid any inconveniences and allow more time given to the interviewer. The respondents were given free choice to participate or not to participate in the study.

\section{Beneficence}

The respondents were assured that the research aim is to strengthen the VHT system in Uganda and improve the welfare of the VHTs and the community.

\section{Confidentiality}

To deal with the issue of confidentiality, the respondents were assured that all information provided was for purely academic purposes and was being treated with the utmost confidentiality.

\section{Limitation of the study}

Limitation of published literature describing factors influencing VHT effectiveness; however, this was overcome through an effort to find more information about the context of the study through 
Table 1. The study unit was the VHT member involved in community health activities of Nabuyoga.

\begin{tabular}{ll}
\hline Study variables & Indicators \\
Incentives & $\begin{array}{l}\text { Type of incentives given for example Recognition How often are they given } \\
\text { Transport for home visit. }\end{array}$ \\
$\begin{array}{l}\text { Supplies availability } \\
\text { Annual support }\end{array}$ & $\begin{array}{l}\text { Dug distributed Immunization carried out Number of bed nets distribute } \\
\text { supervision and training }\end{array}$ \\
\hline
\end{tabular}

the description of other terms used elsewhere such as village Health guides, community health workers who share the same role as VHTs.

Non - responses of respondents are anticipated and this was solved by triangulation through including the local community as respondents.

INTERPRETATION AND ANALYSIS OF FINDINGS.

\section{Demographic data.}

Table 2 reveals that $78 \%$ of the respondents were female and only $22 \%$ were male respondents; $25 \%$ of the respondents were in the age bracket of 45 years and above, $21 \%$ were of 28-33 years, then $20 \%$ were of $22-27$ years, $19.4 \%$ were of $34-39,11 \%$ of $40-45$ and $4.4 \%$ of $16-21$ years.

The table further shows that $67 \%$ were married respondents, $16 \%$ were single $12 \%$ were widows, $5 \%$ were separated and $0.4 \%$ were widowers: $33 \%$ of the respondents were diploma holders, 0.4degree level, $15.4 \%$ never completed secondary level, $12.2 \%$ completed secondary level, $28.2 \%$ completed primary level and $10.1 \%$ did not indicate their education level.

Regarding the duration of residence, $27 \%$ of the respondents had lived in the area for 30 years or more followed by $23 \%$ for 5 years and below, $21.1 \%$ for a period of $6-11$ years, $12-17$ years, $11 \%$ for $18-23$ years, and $6.6 \%$ for $24-29$ years.

Table 3 shows that 80 ( $89.1 \%$ ) out of the 90 respondents pointed out that VHTs have involved in Health sensitization, 38(42.6\%) promoting sanitation and personal hygiene among residences, $4(3.9 \%)$ distributing items to needy households, 67 ( 75.2\%) distributing of deworming tablets, 20(23.3\%) HIVAIDS testing activities, 12(13.9\%) noted domestic violence prevention campaigns, $69(67.4 \%)$ distributing mosquito nets and 9(10\%) immunization of children respectively.

The table indicates that the majority 53(59.7\%) of the respondents have ever received family planning services from VHTs, 24 (27.1\%) stated nutrition services, 20 (23.2\%) noted advice on child feeding, $17(19 \%)$ received deworming tablets, $14(16 \%)$ indicate child immunization and 9 (10\%) have never received any assistance.

The table Indicates $22(24.6 \%)$ of the respondents identified mosquito net usage as the most recognized survey that had ever been carried out , 14(15.4\%) observed water and sanitation survey,2( 2.2\%) noted nutrition survey in Pawanga and Miganja ,3(3.5\%) family planning utilization in HIV/AIDS patients, 2(2.2\%) domestic violence rate in the area , $1(1.3 \%)$ pointed out malaria prevalence in under 5 years respectively, and 45( 50.2\%) did not know .

Forms of incentives received by VHTs

The table reveals that $8(8.8 \%)$ indicated that monetary incentives received, $16(17.5 \%)$ noted social recognition, 17 (19.2\%) indicated that they receive a transport refund after the meetings at the health centers,17(19.2\%) a certificate of appreciation, $13(14 \%)$ pointed out free medical care and 19(21\%) stated self-satisfaction for being useful and resourceful for the village.

Table 7 shows that 37(42.1\%) acknowledged that incentives serve as motivators for attraction and retention of VHTs ,19(21\%) state that they serve as rewards for good performance , 17(19.3\%) agreed that they increase the outreach areas of their services, and $16(17.5 \%)$ state that they increase awareness of VHTs operations in the area.

Table 8 indicates that 33\% noted that there was in consistence in supply of incentives to VHTs, 7\% indicated that supplies are not evenly distributed, $26.3 \%$ recorded that incentives are not adequate compared to the needs, $14 \%$ state the number of times incentives are given is unrealistic, and $19.3 \%$ state lack of transparent mechanism for promotions and rewards.

Availability of supplies for VHT activities

Reaction of respondents on availability of supplies among VHT activities. 
Table 2. shows socio- demographic characteristics of respondents.

\begin{tabular}{|c|c|c|}
\hline Variable & Frequency & Percentage (\%) \\
\hline Gender & 20 & 22 \\
\hline Male & 70 & 78 \\
\hline \multicolumn{3}{|l|}{ female } \\
\hline Total & 90 & 100 \\
\hline Age & 4 & 4.4 \\
\hline $16-21$ years & 18 & 20 \\
\hline 22-27years & 19 & 21 \\
\hline 28-33years & 17 & 19.4 \\
\hline 34-39years & 10 & 11 \\
\hline 40-45years & 22 & 25 \\
\hline \multicolumn{3}{|l|}{46 above } \\
\hline Total & 90 & 100 \\
\hline Marital status & 60 & 67 \\
\hline Married & 14 & 16 \\
\hline Single & 11 & 12 \\
\hline Widows & 5 & 05 \\
\hline Separated & - & 0.4 \\
\hline \multicolumn{3}{|l|}{ widowers } \\
\hline Total & 90 & 100 \\
\hline Level of education & 2 & 1.7 \\
\hline Degree & 28 & 33 \\
\hline Diploma & 11 & 12.2 \\
\hline Completed secondary level & 14 & 15.4 \\
\hline Never completed secondary level & 25 & 28.2 \\
\hline Completed primary level & 9 & 10.1 \\
\hline \multicolumn{3}{|l|}{ Never been to school } \\
\hline Total & 89 & 100 \\
\hline Duration of residence & 24 & 27 \\
\hline 30 \& above & 6 & 6.6 \\
\hline $24-29$ & 10 & 11 \\
\hline $18-23$ & 11 & 12 \\
\hline $12-17$ & 19 & 21.1 \\
\hline $6-17$ & 20 & 23 \\
\hline \multicolumn{3}{|l|}{5 below } \\
\hline Total & 90 & 100 \\
\hline
\end{tabular}

Table 3. shows activities carried out by VHTs in the area known by resident

\begin{tabular}{lll}
\hline & Fre- & Percentage \\
Health sensitization & quency & 89.1 \\
Promoting sanitation \& personal hygiene & 80 & 42.6 \\
Distribution of deworming tablets & 38 & 75.2 \\
Distributing household items to needy households. & 67 & 3.9 \\
Immunization & 4 & 10 \\
Domestic violence prevention & 9 & 13.9 \\
Distributing mosquito nets & 61 & 67.9 \\
HIV/AIDs testing activities & 20 & 23.3 \\
\hline
\end{tabular}

Source: primary data. 
Table 4. Type of assistance received by residents from VHTs.

\begin{tabular}{lll}
\hline & $\begin{array}{l}\text { Fre- } \\
\text { quencycent- }\end{array}$ \\
& $\begin{array}{l}\text { out } \\
\text { of }\end{array}$ & age \\
& 20 & 23.2 \\
Advice on child feeding. & 53 & 59.7 \\
Family planning services & 24 & 27.1 \\
Nutrition services & 17 & 19.0 \\
Receiving deworming tablets & 14 & 16.0 \\
Child immunization & 17 & 19.3 \\
Provision of treated mosquitoes & 9 & 10.0 \\
nets & & \\
Never receive assistance & & \\
\hline Source: primary data. & &
\end{tabular}

Table 9 reveals that 24(79\%) of the respondents noted that they do not receive adequate supplies for service delivery and 6(21\%) do agree that they do receive adequate supplies, 23(75.4\%) agreed that indeed the available supplies are in line with the immediate needs of the community,29(96.5\%) stated that there is no continuous supply of resources, and 25( 84.2\%) notedthat the population weighs the VHTs manpower thus negatively affecting the performance of VHTs.

Likewise, pick w (1995) postulated that poor performance by VHTs is associated with low accessibility and utilization of antenatal can, insufficient supply and distribution of supplements inadequate training and motivation of health workers, insufficient and inappropriate counseling of mothers, lack of motivation of mothers and failure of effective screening and referral procedures.

Support supervision on the performance of VHTs on health promotion

VHT's views as to whether they receive support supervision for health promotion.

The table Indicates that $27(89.5 \%)$ of the respondents noted that they do not receive sufficient support, 50(87.7\%) stated that health staff do not supervise them regularly,23(77.2\%) affirmed that the health staff demonstrate technical skills related health promotion ,21(70.2\%) noted that health staff help them solve problems related to community health issues, still 23(78.9\%) noted that health staff do not provide them with urgent materials needed to extend health services in the communities and $21(70.2 \%)$ state that government rarely supports
VHTs activities to reach out to needy communities respectively.

Effects of insufficient support supervision on VHTs on health promotion

Table shows that 11 (36.8\%)pointed out that government rarely supports VHTs activities to reach out to needy communities respectively.

Effects of insufficient support supervision on VHTs on health promotion.

Table shows that $11(36.8 \%)$ pointed out that insufficient support demoralizes VHTs, 10(31.6\%) affirmed that insufficient support limits service quality, $6(21.1 \%)$ of the respondents stated thatinsufficient support supervision increases VHTs attrition rate, and 21(10.5\%) stressed that insufficient support leads to loss of direction in service delivery

\section{Performance of VHTs}

Level of performance of VHTs on health promotion

Below $50 \%$ indicates the poor performance of VHHTs and above $50 \%$ indicates the good performance of VHTs in the area.

Above $50 \%$ indicates the inadequate provision of incentives, supplies, and support supervision.

$44(74.4 \%)$ of the respondents agreed that evidence for the performance of VHTs in health promotions can easily be found, $43(71.8 \%)$ agreed that sanitation of the area is still poor,42(70.5\%) agreed that there is a considerable reduction in mortality rate,41(68.3\%) agreed that there is disease control in the area, 35(58.6\%)agreed that there is a time delay in responding to health issues in the area ,34(56.8\%) agreed that there is lack of resource materials practitioners use for advise and support about specific challenges and 27(44.9\%) agreed that service quality is not satisfactory.

One of the communities cited that there have been reduced cases of measles in the community due to the advice to mothers to immunize their children.

Constraints/factors that hinder the performance of VHTs on the promotion of health

The table indicates that $13(43.2 \%)$ pointed out reluctance of community members to get involved, $6(22 \%)$ of respondents identified less time commitment by $\mathrm{VHTs}, 9(31.7 \%)$ heavy workload compared to VHT numbers , $3(11 \%)$ stated that communities prefer curative services to prevention measures ,15(51.1\%) stated poor remuneration as a factor that negatively affects the performance of VHTs 
Table 5. different health survey carried out in the area.

\begin{tabular}{lll}
\hline & Frequency out of & Percentage \% \\
Nutrition survey & 2 & 22 \\
Family planning utilization in HIV / AIDS patients & 3 & 3.5 \\
Water and sanitation & 14 & 15.4 \\
Mosquito net usage survey & 22 & 24.6 \\
Child care welfare & 1 & 0.4 \\
Domestic violence rate in the area & 2 & 2.2 \\
Malaria prevalence rate in under 5 years & 1 & 1.3 \\
Do not know & 45 & 50.2 \\
Total & 90 & 100 \\
\hline
\end{tabular}

Table 6. Table 5: kind of incentives received.

\begin{tabular}{|c|c|c|}
\hline & $\begin{array}{l}\text { Fre- } \\
\text { quency }\end{array}$ & Percentage \\
\hline Free medical care & 13 & 14.0 \\
\hline Transport refund & 17 & 19.2 \\
\hline Certificate of appreciation & 17 & 19.2 \\
\hline Social recognition & 16 & 17.5 \\
\hline Self- satisfaction for being useful, resource for village & 19 & 21.0 \\
\hline Monetary incentives & 8 & 8.80 \\
\hline
\end{tabular}

\section{Table 7. Effects of incentives on VHTs performance}

Table 8. reasons to why supplied incentives have not improved on VHT performance.

\begin{tabular}{lll}
\hline & Frequency & Percentage \\
Inconsistence with supply & 30 & 33.3 \\
Not evenly distributed & 6 & 7.00 \\
They are not adequate compared to the needs & 24 & 26.3 \\
The number of times reward incentives are given is unrealistic & 13 & 14.0 \\
Lack of transparent mechanism for promotions and rewards & 17 & 19.3 \\
Total & 90 & 100 \\
\hline
\end{tabular}

Serve motivators for attraction and retention

\begin{tabular}{ll} 
Fre- & Percent- \\
quency & age \\
37 & 42.1 \\
19 & 21.0 \\
17 & 19.3 \\
16 & 17.5 \\
90 & 100 \\
\hline
\end{tabular}

Source; primary data 
Table 9. respondents 'reaction whether there is availability of supplies to VHT activities.

\begin{tabular}{|c|c|c|c|}
\hline \multirow{4}{*}{$\begin{array}{l}\text { Do you receive adequate supplies for } \\
\text { service delivery? }\end{array}$} & & Frequency & Percentage \\
\hline & No & 24 & 79.0 \\
\hline & Yes & 6 & 21.0 \\
\hline & Total & 30 & 100 \\
\hline \multirow{3}{*}{$\begin{array}{l}\text { Are the available in line with the imme- } \\
\text { diate needs of the community? }\end{array}$} & No & 7 & 24.6 \\
\hline & Yes & 23 & 75.4 \\
\hline & Total & 30 & 100 \\
\hline \multirow[t]{3}{*}{ Is there continuous supply of resources } & No & 21 & 96.5 \\
\hline & Yes & 9 & 3.50 \\
\hline & Total & 30 & 100 \\
\hline \multirow{3}{*}{$\begin{array}{l}\text { The population outweighs the VHTs } \\
\text { manpower }\end{array}$} & No & 5 & 15.8 \\
\hline & Yes & 25 & 84.2 \\
\hline & Total & 30 & 100 \\
\hline
\end{tabular}

Source: primary data.

Table 10. VHT's views on whether they receive support supervision.

\begin{tabular}{|c|c|c|c|}
\hline \multirow{4}{*}{$\begin{array}{l}\text { Do the health staff } \\
\text { demonstrate any techni- } \\
\text { cal skills related to health } \\
\text { promotion }\end{array}$} & & Frequency & Percentage \\
\hline & No & 7 & 22.8 \\
\hline & Yes & 23 & 77.2 \\
\hline & Total & 30 & 100 \\
\hline Do the health staff & No & 9 & 29.8 \\
\hline help you solve problem & Yes & 21 & 70.2 \\
\hline $\begin{array}{l}\text { related to community } \\
\text { health issues. }\end{array}$ & Total & 30 & 100 \\
\hline \multirow{3}{*}{$\begin{array}{l}\text { Do the health staff pro- } \\
\text { vide you the material } \\
\text { needed to extend health } \\
\text { services }\end{array}$} & No & 23 & 78.9 \\
\hline & Yes & 7 & 21.1 \\
\hline & Total & 30 & 100 \\
\hline Do the health staff super- & No & 24 & 87.7 \\
\hline vise you regularly since & Yes & 6 & 12.3 \\
\hline you joined & Total & 30 & 100 \\
\hline Government frequently & No & 21 & 70.2 \\
\hline supports / partner with & Yes & 9 & 29.8 \\
\hline VHTs & Total & 30 & 100 \\
\hline Do you receive sufficient & No & 27 & 89.5 \\
\hline \multirow[t]{2}{*}{ support } & Yes & 3 & 10.5 \\
\hline & Total & 30 & 100 \\
\hline
\end{tabular}

Source primary data.

Table 11. shows effects of insufficient support supervision on VHT activities

\begin{tabular}{lll}
\hline & Frequency & Percentage \\
Demoralize the VHTs & 11 & 36.8 \\
It limits service quality & 10 & 31.6 \\
Loss of direction in service delivery & 3 & 10.5 \\
Increase VHTs attrition rate & 6 & 21.1 \\
Total & 30 & 100.0 \\
\hline
\end{tabular}

Source: primary data 
Table 12. shows effects of insufficient support supervision on VHT activities.

\begin{tabular}{lll}
\hline & Frequency & Percentage \\
Demoralize the VHTs & 11 & 36.8 \\
It limits service quality & 10 & 31.6 \\
Loss of direction in service delivery & 3 & 10.5 \\
Increase VHTs attrition rate & 6 & 21.1 \\
Total & 30 & 100.0 \\
\hline
\end{tabular}

Source: primary data

Table 13. respondents 'level of agreement on the performance of VHTs.

\begin{tabular}{|c|c|c|c|}
\hline Indicator & Score & $\begin{array}{l}\text { Fre- } \\
\text { quency }\end{array}$ & $\begin{array}{l}\text { Percent- } \\
\text { age }\end{array}$ \\
\hline \multirow[t]{4}{*}{ Service quality not satisfactory } & Disagree & 14 & 22.9 \\
\hline & Undecided & 19 & 32.2 \\
\hline & Agree & 27 & 44.9 \\
\hline & Total & 60 & 100 \\
\hline \multirow[t]{4}{*}{ Sanitation of the area is still poor } & Disagree & 9 & 14.5 \\
\hline & Undecided & 8 & 13.7 \\
\hline & Agree & 43 & 71.8 \\
\hline & Total & 60 & 100 \\
\hline \multirow[t]{4}{*}{ There is disease control } & Disagree & 10 & 17.2 \\
\hline & Undecided & 9 & 14.5 \\
\hline & Agree & 41 & 68.3 \\
\hline & Total & 60 & 100 \\
\hline \multirow[t]{4}{*}{ Remarkable supply of free health services } & Disagree & 10 & 16.3 \\
\hline & Undecided & 16 & 26.9 \\
\hline & Agree & 34 & 56.8 \\
\hline & Total & 60 & 100 \\
\hline \multirow[t]{4}{*}{ Consideration reduction on mortality rate } & Disagree & 5 & 7.9 \\
\hline & Undecided & 13 & 21.6 \\
\hline & Agree & 42 & 70.5 \\
\hline & Total & 60 & 100 \\
\hline \multirow[t]{4}{*}{ There is time delay in responding to health issues } & Disagree & 9 & 14.1 \\
\hline & Undecided & 16 & 27.3 \\
\hline & Agree & 35 & 58.6 \\
\hline & Total & 60 & 100 \\
\hline \multirow{4}{*}{$\begin{array}{l}\text { There is lack of resources materials and practitioners for advice } \\
\text { and support with regard to specific challenges }\end{array}$} & Disagree & 14 & 22.9 \\
\hline & Undecided & 14 & 22.9 \\
\hline & Agree & 32 & 54.2 \\
\hline & Total & 60 & 100 \\
\hline
\end{tabular}

Source: primary data 
Table 14. ; shows factors that hinder the performance of VHTs on the promotion of health.

\begin{tabular}{lll}
\hline & Fre- & Percentage \\
Reluctance of community members to get involved & quency & \\
Less time commitment & 13 & 43.2 \\
Heavy workload compared to VHTs communities & 6 & 22.0 \\
Preference for curative services poor remuneration & 9 & 31.7 \\
Limited supply of required services & 3 & 11.0 \\
Transport constraints & 3 & 10.6 \\
Lack of male involvement in health promotion & 3 & 9.7 \\
Belief in witch craft & 2 & 7.9 \\
Lack competent VHTs & 2 & 6.1 \\
Poor follow up measures & 6 & 20.7 \\
Poor remuneration & 3 & 9.7 \\
\hline Source: primary data. & 15 & 51.1 \\
\hline
\end{tabular}

,3(10.6\%) agree to limit supplies that VHTs need to perform , 3(9.7\%) recognized transport constraints ,2(7.9\%) indicated lack of male involvement ,2(6.1\%) state that people believe in witch craft , 6(20.7\%) cited the lack of competency among VHTs to perform , and 3(9.7\%) cited that there are poor follow up measures in place .

Interventions that can be taken to improve on $\mathrm{VHT}$ 's performance

Table indicates that 41(45.8\%) noted the need to improve on the supplies needed by VHTs to facilitate services, this was followed by a desire for continuous training of VHTs at 34(37.4\%),33(37\%) of the respondents pointed out the need to improve on transportation of VHTs to respond promptly to the needs of the communities , 16(17.6\%) cited the need to have a meeting place where VHTs can meet those with urgent needs, $16(17.6 \%)$ urge for the involvement of local government in supporting VHT activities and 15(16.3\%) pointed out the need to urge men to get involved .

Health issue still dire in the area.

Table Indicates the difference health issues that are still dire in the area ,47(52.4\%) of the respondents recognized poor drainage in the area, $34(37.4 \%)$ cited malaria as a health problem still affecting the area of study, $38(42.7 \%)$ indicated poor hygiene and sanitation ,14(15\%) pointed out poor nutrition of household especially children , 8(9.3\%) cited drug and alcohol use, 14(15.4\%) cited teenage pregnancies, $9(10.1 \%)$ noted air and water pollution

\section{DISCUSSION OF FINDINGS, CONCLUSION, RECOMMENDATION AND AREAS FOR FURTHER STUDIES}

\section{Discussion of finding and summary}

\section{Demographic data}

The finding in table 1 indicated that the majority $70(78 \%)$ of the respondents were female and only 20(22\%) were male respondents. This was also cited by Wainer (2004) who asserted that, in the majority of countries, women are the primary caregivers. This means, as women make up an increasingly large population of the primary profession, it is important to consider the different needs of female health workers when developing incentives. VHT's have other jobs in addition to their role. They need flexible time to allow them to perform their duties at home, and their workplace. There is a need for effective management in terms of incentives and supervision to initiate female procedures-oriented procedures and mechanisms.

\section{Village health teams \\ Education of VHTs}

Results in Table 1 show that 28(33\%) of respondents are diploma holders and 24(28.2\%) completed primary level. this is in agreement with the ministry of health guidelines which state that VHTs should be literate. 
Table 15. suggestion to mitigate the identified hindrances.

\begin{tabular}{lll}
\hline & Frequency out of 90 & Percentage \\
Improve on transportation & 33 & 37.0 \\
Increase supplies needed by VHTs to facilitate services & 41 & 45.8 \\
Local government 's involvement may be of significance & 16 & 17.6 \\
Men should be urged to get involved & 15 & 16.3 \\
Continuous training of VHTs & 34 & 37.4 \\
Have a place where VHTs can meet those in urgent need. & 16 & 17.6 \\
\hline Source: primary data & &
\end{tabular}

Table 16. shows some of unsolved health issue in the area.

\begin{tabular}{lll}
\hline & Frequency out of 90 & Percentage \\
Poor sanitation & 38 & 42.7 \\
Drainage system is poor & 47 & 52.4 \\
Malaria is still a health problem & 34 & 37.4 \\
Poor nutrition of household especially children & 14 & 15.0 \\
Teenage pregnancies & 14 & 15.4 \\
Drug and alcohol use & 8 & 9.3 \\
Air and water pollution & 9 & 10.1 \\
\hline Source: primary data & &
\end{tabular}

It is widely acknowledged that health workers, as an integral part of the health system, are a critical element in improving health outcomes. The world Health Report 2006: "working together for health" sounded the alarm that without sufficient numbers of adequately trained and supported health workers; there is a significant risk of not attaining the health-related millennium development goals (MDGs), (WHO, 2006). This implies that education and technical knowledge of VHTs is crucial aspect that directly affects the quality of health services.

Accordingly, Dreesch et al., (2005) postulated that evaluations of diseases-oriented programmers have found that the lack of appropriately trained and motivated health workers is one of the major bottlenecks in implementing evidencebased health interventions to improve maternal and child health and to address HIV/AIDS, malaria and tuberculosis. The absence of well-educated and properly managed health workers was also identified as one of the health system constraints to achieve the MDGs, along with poor infrastructure, drugs and supply system, and information system (Travis et al., 2004).

\section{Selection criteria of VHTs}

Results in (figure3) reveal that $77(85 \%)$ of the respondents indicated that they were directly elected,
$3(4 \%)$ through training, and 10(11\%) were voluntarily involved.

According to WHO, VHTs are men and women chosen by the community and trained to deal with the health problems of individuals and the community and to work in close relationship with the health services. They should have had a level of primary education that enables them to read, write and do simple mathematical calculations (WHO1990). Additionally, Witmer et al., (1995) defined a VHT as community health workers stemming from community members who work almost exclusively in community settings and who serve as connectors between health care consumers and providers to promote health among groups that have traditionally lacked access to adequate care. By identifying community problems, developing innovative solutions, and translating them into practice, community health workers can respond creatively to local needs.

The selection of VHTs is a critical factor in the success and performance of VHTs (Ofosu-Amaah, 1983). It is therefore stated that poor selection is the central reason for the continuous "turn- over of VHTs. Additionally, CARE (2002) noted that the participatory selection of community workers before training was key to the success of commu- 
nity projects. This selection criterion ought to be jointly developed and agreed upon between the community members, leaders, and NGOs. In all aspects, the community must be given final responsibility in selecting the VHTs. The sole reason for this is the fact the sustainability and performance of community-based activities are dependent on the level of community participation in the set activity.

\section{Activities performed by VHTs}

VHTs perform a wide range of activities which include health sensitization, promoting sanitation and hygiene practices, distributing deworming tablets among others.

This is an agreement with Ofosu-Amaah (1983) who found that the VHTs are expected to perform a wide range of functions, which according to reports generally include: home visits, environmental sanitation, provision of water supply, first aid, and treatment of simple and common ailments, health education, nutrition and surveillance, maternal and child health and family planning activities, communicable disease control, community development activities, referrals, record - keeping, and collection of data on vital events.

It is also in agreement with the report from M.O.H that pointed out that VHTs and other community volunteers carry out the following at the community level, nutrition assessment of all age categories, carry growth monitoring promotions, counseling at the community level, referral of individuals needing medical attention, follow up of patients and sending reports to the health centers. Some VHTs in therapeutic feeding at health facilities and screening programs include outreach (M.O.H, 2009).

\section{Channels of communication used by VHTs to deliver promotion messages.}

Figure 4indicates that VHTs adopted different channels among which $20 \%$ of the respondents indicated that entertainment means and community were the most used channels for health promotion: this is in support with World Health Organization (WHO) AND THE PLAN American Health Organization (PAHO) that noted, that local and international work, increasingly rely on entertainmentbased strategies to promote healthy lifestyles and behaviors. One of the key vehicles of these health communication campaigns is television drama, particularly soap operas.

Additionally, studies by Signorielli (1993) and Montgomery (1990) reveal that today's citizens are increasingly more exposed to health information through mass media than they are to health information from visits to doctors or health professionals. In many cases, individuals might be exposed to certain health issues only via mass media (Wahl, 1995). A study conducted by Singnorielli( 1990) revealed that for every person who got their information from a physician, 25got it from the media (Atkin and Wallack,1990).

\section{Type of assistance received by residents from VHTs}

Residents receive assistance from VHTs in form of family planning services, advice on child feeding and nutrition, child immunization, and mosquito nets.

These findings are supported by Engle et al. (2000) who stated that community-based programs under many circumstances provide this crucial contact. Their role is partly in improving access to technology and resources, but it is also important in fostering behavior change and, more generally, in supporting caring practices (UNICEF1990). Such programs also play a part in mobilizing social demand for services and in generating pressure for policy change.

Additionally, in the community-based programs, VHTs interact with households to protect their health and nutrition and to facilitate access to treatment of sickness. Commonly, VHTs go regularly to central points in their community for example, for growth monitoring and promotion or are visited at home by a health and nutrition worker.

Incentives on the performance of VHTs towards promoting health services in the area.

The findings of reveal that there is a significant relationship between incentives on the performance of VHTs in health promotions.

This is in line with the findings of (WHO, 2004) which stress that all workers require adequate facilities and conditions to do their jobs properly. While most evidence is anecdotal. The benefits of improving working and living conditions appear to be significant. It is generally understood that health workers value working conditions that include appropriate infrastructure, water, sanitation, lighting, drugs, equipment, supplies, communications, and transportation. Hence, a range of non-financial incentives are needed to complete a package that can attract VHTs especially, training and professional development, improved supervision and management, and gender-sensitive consideration. 
Also, table 6 confirms that there is a positive relationship between incentives and VHT performance on the promotion of health services, the study indicated that both monetary and non-monetary incentives are instrumental in terms of motivating and facilitating VHTs activities. This is in agreement with the study done by Bhattacharyya ET. Al (2001) noted monetary can increase retention. VHTs are poor people trying to support their families. However, he reveals that monetary incentives often bring a host of problems because the money may not be enough, may not be paid regularly, or may stop altogether. Monetary incentives may also cause problems among different cadres of development paying CHWs. Many programmers have used in-kind incentives effectively; this was revealed by Bhattacharyya et al., (2001) argued that non - monetary incentives are critical to the success of any VHT programmer. CHWs need to feel that they are part of the health system through support supervision and appropriate training. Relatively small things, such as an identification badge, can provide a sense of pride in their work and increased status in their communities. Appropriate job aides such as counseling cards and regular replenishment of supplies can help ensure that $\mathrm{CHWs}$ feel competent to do their jobs.

In addition, it is also argued that peer support as working regularly with one or two other VHTs, frequent refresher training, or even VHTs associations serve as indirect incentives that have a positive effect on VHTs performance of VHTs comes down to VHTs relationship with the community. Programmers must do everything they can to strengthen and support this relationship.

First, program planners must recognize the social complexity of communities and that communities are not all alike. Different communities will need different types of incentives, depending on the other job opportunities available, prior experience with VHTs, the economic situation of the community, and other factors. This is the reason why the findings in figure 10 revealed that $18 \%$ of the respondents stated that incentives supplied did not improve on the VHT services in the area and $82 \%$ agreed that incentives improved on the VHT activities.

About the above, the study is in line with Chen et al., (2004) who stated that low salaries, poor working conditions, weak support and supervision, and limited opportunities for professional development are associated with poor VHT outcomes. This is especially so in rural and remote areas where the provision of services is difficult because of limited health budgets and scattered populations living in isolated villages or islands. Thus, improved salaries and benefits are major financial incentives for VHTs to remain in the health sector ( $\mathrm{WHO}, 2004)$.

Therefore, Amare (2009) recommended that to stir up VHT motivation there is a need to involve and train leaders of community anchors such as Idris (burial associations, churches, mosques, youth and women's associations as well as kebele ( community associations ) leaders, to support and motivate CHWs in ways appropriate to their special attributes. they can do so by promoting VHTs and recognizing their work through providing moral support to VHTs, promoting health better practices and providing a forum for VHTs, and facilitating and following up in the implementation of health practices promoted by VHTs.

According to study findings in table 6 , it was found that $19.3 \%$ of the respondents acknowledged that incentives increase the outreach area of their services; this is supported by Walker and Jan (2005) who stated that VHTs increase the coverage and equity of health services delivery compared with alternative modes of the service organization. But most studies, while useful and necessary for decision-making, leave out key elements of VHT programs such as altruism, volunteerism, community norms, reciprocity, and duty; these tend not to be reflected well in estimates of cost-effectiveness.

Still, under incentives on VHTs performance, the study revealed that $42.1 \%$ of the respondents noted that incentives serve as motivators for attraction and retention of VHTs. This is in agreement with Bhattacharyya et al., (2001) who cited that attrition rates for $\mathrm{CHWs}$ were attributed to multiple causes especially to inadequate pay.

The findings in table 7 revealed that there was a lack of a transparent mechanism for promotions and rewards, $7 \%$ noted that incentives are not evenly distributed which infringes on VHT services, $14 \%$ found that the number of times reward incentives are given is unrealistic, $33.3 \%$ noted that there was inconsistency in the supply of incentives to VHTs and $26.3 \%$ stated that they are not adequate compared to the needs. these findings are in support of Janssen (2006)who held that workers with positive attitudes would devote more efforts in their work, and if their organizations rewarded 
them fairly in the exchange process, they are likely to continue investigating their skills, time, and effort this ultimately translates to higher levels of retention. In essence, the social exchange theory implies that positive attitudes as a result of fair rewards by firms enhance workers' willingness to stay in health promotions activities.

\section{Reasons why supplied incentives have not improved on VHT performance.}

The reason why supplied incentives have not improved VHT performance is due to inconsistency in supply, inadequate supplies compared to the need, lack of a transparent mechanism for promotions and rewards, and the number of times rewards are given.

These results are supported by Dieleman et al., (2003) who argued that a transparent mechanism for promotions and rewards is positively associated with the performance of VHTs if the essence of incentives is to be felt by VHTs, a study carried out in Vietnam, revealed that rural health workers demonstrated that those seeking to upgrade their skills through training for a diploma or certificate did not understand the criteria for the selection of candidates and therefore felt that the process was arbitrary. Whereas in Nepal, health workers in rural areas were critical of a policy that offered the potential for sponsored higher education abroad but did not link these opportunities to perform (Ferrinho et al., 2004). Better information, communication, job descriptions, accountability, and criteria for rewards could increase transparency and health worker motivation.

\section{Availability of supplies on the performance of VHTs towards promoting health services in the area.}

The findings indicate that there is a significant relationship between the availability of supplies on the performance of VHTs.

According to (WHO, 2004) the provision of essential supplies and specialized training is significant for the promotion of health services. Resources are limited and training opportunities are scarce. A way of improving training opportunities, which was suggested by the WHO migration study, involves using open learning courses to provide updated knowledge to medical staff. Making it less likely to 'lose' them as a result of a combination of favorable overseas experience and lack of job satisfaction at home.
Caldwell (2002) contended that the availability of a range of supplies is of paramount importance in determining the effectiveness of services. Therefore, expansion in the availability of supplies makes accessibility of these services affordable.

There is a need for a positive correlation between the availability of supplies and better health outcomes, as well as increased coverage of essential health interventions. These correlations have been demonstrated in several cross-country ecological analyses (Anand and Barnighausen, 2007). The current system of health services and settings is often poorly equipped to meet the diverse acute and preventive health needs of communities (Lawrence, 2009). Although there is an urgent need for health services, many people remain undeserved due to limited supplies needed to meet the high demand hence limiting the performance of VHTs.

It should also be noted that not only is there a lack of equipment but also the supply of competent VHTs to meet the ever-increasing demand for health care.

This is following the World Health Report 2006, which estimated that the world lacks about 4 million health workers if a minimum level of health outcomes is to achieve (WHO, 2006). The report identified 57 'crisis'countries as being the most affected by this dearth in health personnel, predominantly in Sub-Saharan Africa and Asia. Such shortages are symptoms of a poorly managed health workforce and health care system. The causes of the crisis are complex and have to do with insufficient production capacity, but also with an inability to keep the workers that are being produced in the places where they are most needed. Therefore, because of the complex web of factors that influences the mobility of health workers, any efforts to scale up the health workforce in response to the crisis must be combined with effective measures to attract and maintain both existing and newly trained health workers where they are needed most. Notably, in the majority of countries, rural and remote areas are usually lacking sufficient numbers of health workers. Approximately one-half of the global population lives in rural areas, but these areas are served by only $38 \%$ of the total nursing workforce and by less than a quarter of the total physicians' workforce.

Support supervision on the performance of VHTs towards promoting health services in the area. 
The chi-square test finding indicated that there is a positive relationship between support supervision and performance of VHTs, thus rejecting the null hypothesis.

These findings are in line with Holland and Adams (2002:228) who pointed out that the right supervision supports professional development, enhances personal

and collaborative inquiry, promotes critique, and helps people learn. To this, Acheson and Gail (2003) highlighted that supervision is not autocratic but collaborative and interactive. Furthermore, it is not directive but democratic. It is also more teacher-centered rather than being an authoritative supervisor-centered activity. Dieleman (2003) puts it aptly when he stresses that the supervisor can be seen as "a teacher of teachers" .thus, Sachs (20030 observed that health workers are engaged in a wide variety of tasks which are added to face -to face teaching .system appear to be demanding

more and more of VHTs. these extra duties include; health pedagogy design and development; planning marketing and community relations. further still, young (1998) claims that morale is often influenced more by outside factors than internal ones. Rogers(1992) identifies both internal and external factors as influencing morale, highlighting 'pace of bureaucratic change; discipline and management concerns; staff and staff relations; time and workload pressures ' as the most common stressors for VHTs.

Therefore, the significance of supervision is based on the notion that support supervision which enhances professional development opportunities encourages VHTs to engage in critical thinking about current ways of teaching, develop new approaches, and evaluate how new interventions affect service quality (Kellecher,2003) .effective professional development changes VHTs 'values, beliefs, and practices to positively impact health

promotion (Mc Donald,2009); Desimone

et.al.2006). However, professional development should not be

held in the traditional division-sponsored or oneday workshop manner because that type of professional development focuses on transmitting

knowledge to VHTs rather than VHTs constructing and internalizing

knowledge ( Mc Donald,2009). Therefore, effective professional development for improving VHTs performance encompasses long-term com- mitment, reflective practice, and collaboration to change

health practices (McDonald,2009; Stronge,2002). W.H.o (2006) Postulated that good supervision and management should include adequate technical support and feedback recognition of achievements, good communication, clear roles and responsibilities, norms and codes of conduct which are critical to the performance of the health system and the quality of care. Weak support supervision and management have been identified as a factor in job dissatisfaction in many countries, in this case among VHTs in Uganda (WHO, 2004)

According to the findings of this study in table 10 revealed that $50 \%$ of the respondents noted that they do not receive regular supervision from health staff. This is in line with Ofosu-Amaah (1983) and Bhattacharyya et.al (2001) who asserted that the success of VHT programs hinges on regular and reliable support and supervision. It Is equally acknowledged, however, that supervision is often among the weakest links in CHW programs in the nation.

W.H.O (1990) reported the weakness of support supervision in VHTs 'activities, which are often irregular or nonexistent, and it accounts for poor service delivery among VHTs. It is further noted that in the worst cases, VHT does not even know who their supervisors are or what they can expect from them (Gray and Ciroma, 1988). Gilson et.al (1989) pointed out that often the need for supervision has been either overlooked or underestimated or not adequately planned for also the supervisor's knowledge of what their tasks are often ill-defined. OfusuAmaah (1983) revealed that supervision is often left mostly to staff (mainly nurses) in the health services instead of community participation since in most cases community supervision has recorded multiple successes. They, however, may not understand the CHWs 'or their role properly and may resent the additional task (Gilson et.al 1989). Most importantly, however, the greatest need for supervision exists in the most remote areas, where health services are most overstretched and ill-equipped.

Following the study findings, $45 \%$ of the respondents noted that health staff do not provide them with urgent materials

needed to extend health in the communities and government

rarely support VHTs activities to reach out to needy communities respectively. This was echoed 
by Stinson et.al (1998) who found that, although supervision is often identified as the vehicle through which the quality of health care services can be assured, it typically receives neither the human nor financial support needed to fully conduct and sustain the necessary supervisory activities. In the current decentralization of health services management occurring in many countries, full responsibility for the supervision of facility and community health workers has been shifted to area and district levels, often without providing the training and resources needed to undertake supervisory functions.

Furthermore, the activities with which supervisors are charged are often poorly defined. Health care systems have a wide range of options in developing a locally appropriate and sustainable supervision strategy at the primary level. key issues are who supervision of facility and community health workers has been shifted to area and district levels, often without providing the training and resources needed to undertake supervisory functions.

Accordingly, the study in table 10 revealed that insufficient support increases the VHT's attrition rate; this is in agreement with Charleston (1994) in their study of the impact of a nutrition intervention on a CHW programmer. They found that continuous supervision diminishes the sense of isolation that VHTs usually experience in the field and helps to sustain their interest and motivation to do their assigned tasks (Charleston, Johnson\& Tam, 1994).

Further still, of the respondents affirmed that insufficient support limits service quality, 36. 8\% pointed out that insufficient support demoralizes VHTs and $10.5 \%$ stressed that insufficient support leads to loss of direction in service delivery. This is in light of Gilson et.al (1989) who noted that support supervision works hand in hand with other forms of support, in particular logistics and infrastructure support. Issues such as the reliable provision of transport, drug supplies, and equipment have been identified as another weak link in VHTs performance. Reasons can gain be found in the fact that VHTs, as a rule, operate on the periphery, both organizing and geographically. They are the first to lose training opportunities and supervisory visits, but also transport and drug supplies (Gilson et.al 1989). The result is not only that they cannot do their job properly, but also that their standing in communities is undermined. Failure to meet the expectations of these populations destroys the credibility of the VHTs (Ofosu- Amaah ,1983). if CHWs are used are

used in programmers that have

drug treatment at their core, the situation becomes more critical ( farmer et al.2001), but most programmers include the need for supply of drugs and/or equipment, including transport (SOCHARA, 2005).

Also, lack of a support system in the health sector negatively affects outcomes for instance Bhattachryya.K, et .al (2009)noted that training is a means of supervision. It is well established and accepted that careful and regular supervision impacts profoundly on the quality of service delivery. Without supervision, staff easily feel unappreciated and insecure, particularly in the implementation of new policies and treatment regimes.

This sense of insecurity and lack of appreciation may in turn lead to disenchantment with, and resistance to the information process in the health sector and hence render the health services insufficient. Yet despite overwhelming agreement on its importance, support and regular supervision remain one of the weakest aspects in the health sector. Both national and local government health departments must explore mechanisms to improve supervision, particularly of staff working at lower levels of the service and in rural areas. This requires skills development of supervisors, but also the incorporation of supervisory duties into contracts and workloads of professionals employed at different levels of the service (including in provincial and regional tertiary and secondary level facilities). While nurses in primary care facilities

must be obligated and enabled to accompany CHWs on their rounds in communities, professionals working in management, academic institution, and hospitals might in their performance agreement be required to spend part of their time supporting and supervising nurses and managers in clinics,sub-districts, and districts.

Amongst the 22 respondents issued in its taskshifting guidelines, the WHO proposed that:' countries should define the roles

and the associated competency levels required both for existing cadres 'VHTs' that are extending their scope of practice and for those cadres that are being newly created under the task shifting approach ' .these standards should be the basis for establishing recruitment, training, and evaluation criteria (WHO,2008). Support supervision and 
clinical mentoring should be regularly provided to all health workers within the structure and functions of health teams. Individuals who are tasked with providing support supervision or clinical mentoring to health workers to whom tasks are being shifted should themselves be competent and have appropriate supervisory skills in this way, the performance of VHT can be enhanced (WHO, 2008).

Additionally, WHO pointed out that countries need to recognize that essential services cannot be provided by people working voluntarily if they are to be sustainable, while volunteers can make a valuable contribution on a short term or part-time basis, trained health workers who are providing essential health services, including community health workers, should receive adequate wages and /or other appropriate and commensurate incentives (WHO, 2008).

Factors that hinder the performance of VHTs in health promotions.

ndicates that among the factors that hinder the performance of VHTs is the reluctance of community members to get involved, less time committed to VHT activities, lack of men's involvement, and transport constraints among others.

Similarly, WHO, (2006) noted that dramatic inequities, but also insufficient absolute numbers of health personnel, have been identified as one of the key impediments in the improvement of health system performance worldwide. The 2006 World Health Report puts the global shortage of health workers at 4.3 million. The lack of skills is aggravated by insufficient supervision, particularly in rural areas where community service VHTs find themselves as the only doctors in health facilities. Not only do they find themselves often knowing what to do, but also not knowing who to ask for instance (Reid S, 2003).

Also the study attitudes as serious to the quality hindrance to the quality of health promotion as it was noted by Gilson et al., (1989)who stated the

attitudes and interactions of health personnel in the formal health services with $\mathrm{CHWs}$ have an immediate impact on critical aspects of CHW69programme management, such as selection, continuing training, and supervision. In many cases, these interactions have been affected by how programs have been introduced. CHW programs have commonly been advocated by enthusiasts with local experience, who persuade policymakers to scale up the initiative and imple- ment programs on a large scale. This has frequently resulted in the implementation of inadequate thought-though schemes without the full participation of health personnel at the local level. In many programs, the VHTs are usually not involved in the planning, implementation, monitoring, and evaluation of such programs which makes them lend little support to those initiatives.

Among the measures suggested to improve VHT performance include improvement on transportation, local government's involvement, continuous training of VHTs, and encouraging men to get involved.

in the same vein, Moore et.al (2007) asserted that the use of mid-level health workers plays an important role in VHT health promotion, as it widens access and coverage, and ensures service delivery in areas, which are otherwise severely underserved. International experience suggests that mid-level workers if properly trained and supported, can render health care within their scope of practice, which is of equal or better quality than that rendered by health professionals.

likewise, the training mid-level and community based requires acceleration and standardization. if VHTs associates are to substantially strengthen staffing in community health programs shortly, numbers of trainees should be substantially increased and their training

and deployment carefully monitored. the training of CHWs remains wholly unsatisfactory .while certain minimum standards have been set in the policy, these are not being met. regional health departments should ensure that staffing, resources, and infrastructure for the compulsory training of all CHWs are available, and that training is conducted as well as monitored regularly and reliably Steinlechner et al.(2006).

Health issues still dire in the area

Among the health, still dire in the area include poor sanitation and drainage, malaria, teenage pregnancies, poor nutrition, and drug and alcohol abuse.

The findings are in line with the 1997 Kampala Declaration on sanitation (KDS) guides that found that the promotion of hygiene and sanitation in Uganda is still poor, for example, national latrine coverage is at $62.4 \%$ and this is below the target of $70 \%$ at the end of HSSP11. The situation is worse in some districts such as Abim, Kabong, Kotido Nakapiripiriti, and other rural and slum 
areas, where latrines coverage is less than 10\%, and housing conditions are also poor with threequarters of the households having floors made of earth, sand or drug .only $14 \%$ of the persons wash hands with soap against a target of $70 \%$.overall during the HSSP II period there was a decrease in the incidence of diarrhea diseases. the annual incidence of cholera fell from15/100,000 in 2005 to $3 / 100,000$ in 2009 and that of dysentery decreased from288/100,000 in 2005254/100,000 in 2009. There was also a decrease in the case fatality rate of diarrhoeal diseases. cholera case fatality

rate ( CFR) FELL FROM $2.5 \%$ IN 2005 TO 2.1\% I 2009 ; dysentery CFR from $0.11 \%$ in 2005 to $0.08 \%$ ; and acute watery diarrheas case fatality rate

Fell from $1.2 \%$ in 2006 to $0.9 \%$ in 2009; but persistent diarrhea CFR increased from $0.7 \%$ to $1.3 \%$ .inadequate resources, high level of poverty, inadequate awareness, poor enforcement of public health bye-laws, and cultural factors in some

regions ( e.g. in Karamoja) are major challenges that have affected the implementation of environmental health programs.

In brief, the study is in agreement with earlier findings that revealed that the health conditions in Uganda are still bad. And these can partly be attributed to the poor incentive packages, limited availability of supplies, and weak support supervision system (Ministry of Health, 2009).

Relationship between incentives, availability of supplies, and support supervision on the performance of VHTs on health promotion.

Findings have revealed that there was a positive association between incentives, availability of supplies, and support supervision on the performance of VHTs in health promotion. Those findings are supported by the study of CARE (2002) that sustainability of the community-based workers is not only dependent on the provision of financial and other resources, but equally, on effective and good supervision .these two are almost equally expensive, yet critical.

It is stated that the operational environment has many different actors, with different cultures and approaches, and should be streamlined to avoid the creation of too much dependence, or occasions where communities hold projects at ransom for salaries and other material benefits .for sustainability, community action plan generated at village/parish levels for improved health care directly related to adopted incentives, availability of sup- plies and support supervision; in line with community participation and leadership and other funding or service providing partners for implementation rather than only to the mother organization (Care,2002).

In a similar vein, Fowler(1996) suggested that supervision provided on an individual basis aims to enable the supervisee to do the job better and to provide informed, enhancing interaction, such as professional support, role development, improving confidence, intra-and 72inter-professional networking, and improved job control and satisfaction to improve students' outcomes.

\section{Conclusion.}

In conclusion, the study has found the significance of VHTs in promoting health practices to be positive .results have substantially revealed that in the presence of well-facilitated VHTs, the health conditions of Nabuyoga Town Council can be actualized this implies that the performance of VHT activities is dependent on the adopted incentives, availability of supplies and support supervision .once these aspects are well managed and channeled to VHTs then the levels of health conditions will be realized.

Hence, results suggest that there should be comprehensive management strategies in terms of incentives to increase recognition and social acceptance of VHTs to increase job satisfaction and motivation .following a study of rural health workers in northern Vietnam, it was revealed that appreciation by supervisors, colleagues, and the community was a major motivator.(Dieleman et .al., 2003) .these findings assert the importance of incentives on VHT activities from within and out. the lack of positive feedbacks when the VHTs performed well negatively affected the health outcomes of VHTs.

In addition, the study has revealed that the lack of adequate and regular supply of key inputs or facilitates negatively affected VHTs performance; it shows the progress of accessing the neediest people in remote areas .likewise, the significance of support supervision has also been established to be positively associated with the performance of VHT activities.

On the other hand, the study found that women were the main participants in VHT activities compared to their counterparts the men. Also, it is widely presumed that the reluctance of men to be involved in VHTs negatively impacted the perfor- 
mance of the health practices. In short, incentive packages are used as a means to attract, retain and motivate VHTs; thus they should be embedded in comprehensive workforce planning and development strategies. Availing supplies needed by VHTs are essential for the sustainability of health projects; and lastly, encouraging support supervision is of great significance in terms of enhancing technical skills, motivating, and keeping the VHTs positively committed to the advancement of health promotion.

An effective management system needs to have the capacity to regularly assess the performance of VHTs and engagement of well- trained health workers in the supervision of VHTS This may be difficult in rural and remote areas where supervision and management are weak, the simplified system can be developed, drawing on health workers themselves to assist in designing a system.

\section{Recommendation.}

Based on the study findings, the researcher suggests that to ensure sustainability and good performance of VHTs, it would be worthwhile to improve on incentives given to VHTs especially transport refunds for them to respond promptly to the local needs.

There is also a need to improve the supply offered to the communities through VHTs.the services need to be consistent and based on locally relevant priorities and issues identified by various community representatives.

There is a need for continuous supervision and training of VHTs and their supervisors especially in the area of record-keeping and report making. the community members can be involved in the supervision and monitoring of VHT activities in the areas.

These recommendations are derived from the fact that community members are the main stakeholders that can positively and constructively support the success of VHT activities in terms of incentives, supplying simple but sound inputs, and offering support supervision on the activities carried out by VHTs. Hence community -based monitoring involves drawing in, activating, motivating, capacity building, and allowing the community and its representatives, for example, community-based organizations (CBOs), people's movement, and voluntary organizations to directly give feedback about the functioning of VHT health services. the community monitoring process involves a three-way partner- ship between healthcare supervisors and providers (health system); the community,community-based organizations. The emphasis is based on the development spirit of fact-finding and 'learning lessons for improvement 'rather than 'fault-finding. Garg and Laskar, (2009).

\section{Area of further studies.}

Based on the investigation, the researcher suggested that there should be a further study in examining the prevalence of attrition among VHTs in the Nabuyoga town council. The rationale of this gesture is the fact that attrition of VHTs negatively affects the health sector in the area since VHT's activities are said to be associated with wide service coverage when supported by local and national institutions.

\section{ACKNOWLEDGMENT.}

First and foremost, I wish to express my most sincere gratitude to my supervisor, Mr. Aluma Franco for the untiring support and exceptional guidance throughout the entire course. Your constant help made this work possible.

Also, I would like to appreciate the special people who have offered support in completing this thesis such as Madam Komugisha Agnes, and the tutors.

Last but not least to my wife and children. I am is so grateful for your love and prayers.

My special thanks also to my family in particular my wife Naume for the encouragement and spiritual support accorded to me at all times I leave home most especially during study trips to St. Francis Mukono.

The moral and material assistance from all my friends especially Justine, Charles, and Joyce were so much that without their support the internship exercise would have not been completed on time.

Finally, to the respondents, who willingly spared their precious time to participate in this study, thank you very much?

You will always have a special place in my heart. 
Table 17. references

1) Angela, N. (no date) 'ASSESSMENT OF FACTORS INFLUENCING PERFORMANCE OF COMMUNITY HEALTH WORKERS IN HEALTH CARE DELIVERY IN MITYANA DISTRICT, UGANDA', p. 95.

2) Amare, y. (2009) 'Non -financial incentives for voluntary community health workers: An Association Report .ground up-a PELUM publication promoting sustainable agriculture.pg26,www.hrhresourcecentre.or g/node/3193.september2010.

3) Bhattacharyya ET. Al (2001), community Health worker incentives and disincentives: how they affect motivation, retention and sustainability, www.hciproject.org, pdf June 2011

4) . Dieleman, M,ET.al. (2003),'identifying factors for job motivation of rural health workers in North Vietnam .India journal of community medicines, 35https://doi.org/10.1186/1478-4491-1-10PMid:14613527 PMCid:PMC280735

(2) pg. 214-216. Vol1.No.5:4.www.human -resource .com/ content/1/1/10 July 2011.

5) Faith, N. (no date) 'FACTORS INFLUENCING THE PERFORMANCE OF VILLAGE HEALTH TEAMS (VHTS) IN HEALTH PROMOTION, A CASE STUDY OF MAKINDYE DIVISION', p. 101.

6) Garg and Laskar, (2009). Community Based Monitoring: Key to success of national health programs .ww w. En. commons. orgjune2011.

7) HSSIP (2010/11-2014/15). , promoting people's health to enhance socio-economic development, ministry of health, www.health .go.ug/docs/HSSIP10.pdf.2010/11-2014/15 July HSSIP (2010/11-2014/15).September 2010. 